\title{
Multidrug resistance, biofilm formation, and virulence genes of Escherichia coli from backyard poultry farms
}

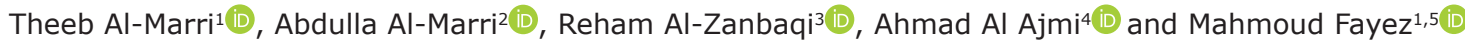

1. Al Ahsa Veterinary Diagnostic Laboratory, Ministry of Environment, Water and Agriculture, Al-Ahsa 31982, Saudi Arabia; 2. Veterinary Diagnostic Laboratory, Department of Animal Resources, Doha, Qatar; 3. Veterinary Diagnostic Laboratory, Ministry of Environment, Water and Agriculture, Riyadh, Saudi Arabia; 4. The Central Laboratories for Veterinary, Agriculture, and Fisheries, East Amghara 21422, State of Kuwait, Kuwait; 5. Department of Bacteriology, Veterinary Serum and Vaccine Research Institute, Ministry of Agriculture, Cairo 11381, Egypt.

Corresponding author: Mahmoud Fayez, e-mail: mahmoudfayez30@hotmail.com

Co-authors: TA: theep8@hotmail.com, AA: a.almarri@hotmail.com, RA: reham.alzanbaqi@alumni.acphs.edu, AAA: Ahmad.al_ajmi@yahoo.com

Received: 22-07-2021, Accepted: 04-10-2021, Published online: 10-11-2021

doi: www.doi.org/10.14202/vetworld.2021.2869-2877 How to cite this article: Al-Marri T, Al-Marri A, Al-Zanbaqi R, Al Ajmi A, Fayez M (2021) Multidrug resistance, biofilm formation, and virulence genes of Escherichia coli from backyard poultry farms, Veterinary World, 14(11): 2869-2877.

\begin{abstract}
Background and Aim: Backyard chicken flocks have traditionally been regarded as an essential food source in developed countries; however, they may act as reservoirs and spread various zoonotic bacterial pathogens. This study was designed to investigate the prevalence, phenotypic resistance, biofilm formation (BF), and pathotypes of Escherichia coli isolates from backyard poultry farms.

Materials and Methods: Cloacal swabs $(n=150)$ and internal organs $(n=150)$ were collected from 30 backyard chicken flocks; 20 of them were experiencing systemic infection, and the other ten were apparently healthy. Samples were bacteriologically

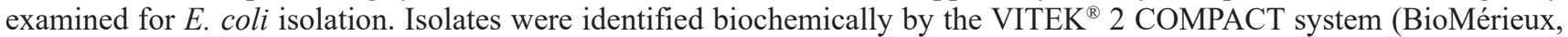
France). For molecular identification, $16 S \mathrm{~S} R N A$ was amplified and sequenced. Ten antimicrobials were selected for $E$. coli antimicrobial susceptibility testing. The minimum inhibitory concentration for each antimicrobial was determined. The extended-spectrum $\beta$-lactamase activity in isolates was investigated using cephalosporin/clavulanate combination disks. The ability of isolates for BF was determined by the microtiter plate method. Thirteen virulence genes linked to different $E$. coli pathotypes and two serotype-related genes were investigated by real-time polymerase chain reaction.
\end{abstract}

Results: Eighty-six E. coli strains were isolated from 30 backyard chicken flocks. The isolates were biochemically identified to the species level. Genetically, sequences of the $16 \mathrm{~S}$ rRNA gene showed $>98 \%$ identity with E. coli in the National Center for Biological Information database. The frequency of isolation from diseased flocks was significantly higher $(\mathrm{p}<0.05)$ than apparently healthy flocks; $63.9 \%$ of the isolates were recovered from cloacal swabs and $36.04 \%$ were recovered from internal organs. E. coli isolates showed high resistance to ampicillin (AMP; 75.6\%), gentamicin (39.5\%), and tetracycline (29.1\%). However, none of the isolates were resistant to imipenem. A variable drug resistance profile for $E$. coli isolates was reported. Twenty-one $(24.4 \%)$ isolates were sensitive to all ten antimicrobials. Seven $(8.1 \%)$ isolates were resistant only to AMP, and $28(32.6 \%)$ were resistant to two antimicrobials, whereas the remaining $30(34.9 \%)$ isolates showed multidrug resistance (MDR). Of the 86 isolates, 8 (9.3\%) were confirmed as extended-spectrum $\beta$-lactamase (ESBL)-producing $E$. coli by the combination disk diffusion method. All ESBL isolates were MDR with an MDR index of 0.5-0.6. Fifty-seven (66.3\%) isolates were capable of forming biofilms; $22(25.6 \%)$ of them were strong biofilm producers, $24(27.9 \%)$ moderate producers, and $11(12.8 \%)$ weak producers. A statistically significant pairwise correlation was obtained for MDR versus BF $(r=0.512)$ and MDR index versus BF ( $\mathrm{r}=0.556)$. Based on virulence gene profiles, five pathotypes were identified, including enteropathogenic E. coli (39.5\%), avian pathogenic E. coli (32.53\%), enterohemorrhagic E. coli (EHEC; 9.3\%), enterotoxigenic E. coli (ETEC; $5.8 \%$ ), and enteroaggregative E. coli (EAEC; $1.2 \%$ ). The lower frequency of EAEC and ETEC was statistically significant than other pathotypes. Three isolates were identified as $\mathrm{O} 157$ based on the detection of the $r b f O 157$ gene.

Conclusion: This study reported a high prevalence of MDR, suggesting the misuse of antimicrobials in backyard chicken farms. The emergence of ESBL and EHEC isolates in backyard chickens is a public health concern. Furthermore, the backyard flocks environment may harbor different pathogenic bacteria that may enhance the persistence of infection and the transmission to in-contact humans. Regular monitoring for the occurrence of MDR and the zoonotic pathotypes among E. coli in backyard chicken flocks is recommended, as these bacteria can transmit to humans through food products or contaminated environments.

Keywords: backyard broilers, Escherichia coli, multidrug resistance, virulence genes.

Copyright: Al-Marri, et al. Open Access. This article is distributed under the terms of the Creative Commons Attribution 4.0 International License (http://creativecommons.org/licenses/ by/4.0/), which permits unrestricted use, distribution, and reproduction in any medium, provided you give appropriate credit to the original author(s) and the source, provide a link to the Creative Commons license, and indicate if changes were made. The Creative Commons Public Domain Dedication waiver (http:// creativecommons.org/publicdomain/zero/1.0/) applies to the data made available in this article, unless otherwise stated.

\section{Introduction}

Escherichia coli is a facultative anaerobic Gramnegative bacterium of the family Enterobacteriaceae. It is ubiquitous in the intestine of humans, animals, and birds as part of the intestinal flora. However, several strains that have acquired specific virulence genes have been incriminated in intestinal and extraintestinal 
infections [1]. Based on the combination of virulence genes, pathogenic E. coli are grouped into six pathotypes: Enterohemorrhagic E. coli (EHEC), enteropathogenic E. coli (EPEC), enteroinvasive E. coli, enterotoxigenic $E$. coli (ETEC), and diffusely adherent E. coli [2]. E. coli pathotypes incriminated in extraintestinal infections have been named Extraintestinal Pathogenic E. coli [3]. In poultry, avian pathogenic E. coli (APEC) is responsible for extraintestinal infections, causing colibacillosis [4].

EHEC strains encode the Shiga toxin gene and elaborate the Shiga toxin, causing life-threatening problems in humans following systemic absorption. They have been associated with hemolytic uremic syndrome and hemorrhagic colitis in humans, requiring hospitalization and extensive care, with significant mortality in children and the elderly [5]. ETEC binds to small intestinal enterocytes and secretes heat-stable and/or heat-labile enterotoxins, causing watery diarrhea. EPEC also binds to small intestinal enterocytes and destroys the normal microvillar architecture, resulting in inflammatory changes and diarrhea [6].

Animals and birds have been reported as reservoirs for pathogenic $E$. coli, which can spread between them and other livestock. Moreover, feces from reservoirs contaminate the environment; hence, humans become at risk of infection through direct contact with carrier animals or consumption of contaminated water and food [5].

Antibiotic resistance has been identified as a global public health issue. International health organizations have now elevated antibiotic resistance to one of the top health concerns of the $21^{\text {st }}$ century. E. coli has been used to monitor antimicrobial resistance in food animals because it is ubiquitous in the intestine. Moreover, some E. coli isolates carried by poultry are recognized as a potential source of antimicrobial resistance genes that may transmit to humans $[7,8]$.

Biofilms are defined as the matrix that encloses bacterial populations that have aggregated to each other and adhered to surfaces and/or interfaces [9]. Biofilms are a significant public health issue because of their association with bacterial resistance to antimicrobials. Biofilm-associated bacteria can be up to 1000 times more resistant to antimicrobial therapy than their counterparts in the planktonic phase [10]. Regarding E. coli, biofilm formation (BF) contributes to the occurrence of different infections and makes their eradication difficult. The prevalence, mechanism of formation, and medical impact of biofilm in $E$. coli from humans, animals, and birds have been reviewed [11,12].

In Saudi Arabia, E. coli resistance profiles and pathotypes have been identified in human, animal, and food samples [13-17]. However, to the best of the authors' knowledge, no accessible literature has documented E. coli pathotypes and phenotypes from backyard broilers in Saudi Arabia. Accordingly, this study aimed to investigate the prevalence, phenotypes, BF, and pathotypes of $E$. coli strains in backyard broilers.

\section{Materials and Methods}

\section{Ethical approval}

The study was approved by the Animal Ethics protocols established by the National Committee of Bio-Ethics, King Abdul-Aziz City of Science and Technology, and Royal Decree No. M/59.

\section{Study period and location}

The study was conducted from November 2019 to December 2020. The study was carried out in Al-Hofuf city, in the eastern region, Saudi Arabia (N25 22 44.12, E49 35 12.51).

\section{Samples}

Cloacal swabs and internal organs (liver, heart, blood, and air sacs) were collected from backyard broiler flocks $(\mathrm{n}=20)$ experiencing systemic infections (deaths with or without respiratory signs and diarrhea).

Five live diseased birds from each flock were autopsied, and internal organs were aseptically collected in a sterile screw-capped container. Cloacal swabs were collected by vigorous swabbing of the mucosal wall. In addition, control non-diseased flocks $(n=10)$ were sampled as described in diseased flocks. The collected samples were labeled and transported cooled to the laboratory for processing and bacteriological examination.

\section{Bacterial isolation}

Swabs and internal organs were streaked onto MacConkey agar, sorbitol MacConkey agar (SMA), and incubated aerobically at $37^{\circ} \mathrm{C}$ for $24 \mathrm{~h}$. Lactosefermenting colonies (pink colonies) on MacConkey agar and white colonies on SMA were selected and subcultured on brain heart infusion agar for purification. The purified colonies were subjected to Gram staining and oxidase test. Colonies were oxidase-negative, and Gram-negative bacilli were identified biochemically to the species level by the VITEK ${ }^{\circledR} 2$ COMPACT system using GN identification cards (BioMérieux, France).

\section{DNA extraction and 16S rRNA gene amplification and sequencing}

Total genomic DNA was extracted from biochemically identified isolates using the QIAamp DNA mini-kit (Qiagen SA, Courtaboeuf, France) according to the manufacturer's instructions. The $16 S$ rRNA gene was amplified using the universal primers $27 \mathrm{~F}$ (5'-AGAGTTTGATCCTGGCTCAG-3') and 1492R (5'-TACGGYTACCTTGTTACGACTT-3') according to Weisburg et al. [18]. Polymerase chain reaction (PCR) products were purified (QIAquick PCR Purification Kit, Qiagen, France) and sequenced using an ABI 3500 Genetic analyzer (Applied Biosystems, USA). Sequences were subjected to analysis through the National Center for Biological Information (NCBI) Basic Local Alignment Search Tool (https://blast.ncbi. nlm.nih.gov/Blast.cgi). 
Phenotypic detection of ESBL-producing $E$. coli (cephalosporin/clavulanate combination disks)

A standard disk diffusion test was performed according to the Clinical and Laboratory Standards Institute standards and guidelines [19]. Ceftazidime $(30 \mu \mathrm{g})$ and cefotaxime (CTX $30 \mu \mathrm{g})$ disks with or without clavulanate $(10 \mu \mathrm{g})$ were used for the phenotypic confirmation of the presence of ESBLs in E. coli. ESBL production was considered when there was a difference of $\geq 5 \mathrm{~mm}$ between the zone diameters of either of the cephalosporin disks and their respective cephalosporin/clavulanate disks [19].

\section{Antimicrobial susceptibility}

Ten antimicrobials (nine antimicrobial classes), including ampicillin (AMP), amoxicillin-clavulanate (AMC), CTX, cefoxitin (FOX), imipenem (IPM), gentamicin (GEN), ciprofloxacin, tetracycline (TCY), trimethoprim/sulfamethoxazole, and azithromycin, were selected for $E$. coli antimicrobial susceptibility testing. The minimum inhibitory concentration (MIC) for each antimicrobial was determined according to standards and guidelines [19].

\section{Quantitative detection of biofilm}

The microtiter plate (MTP) method described by Naves et al. [20] was used to quantify BF. Purified isolates were grown overnight in $15 \mathrm{~mL}$ trypticase soy broth (TSB) (Oxoid, UK) supplemented with 1\% glucose at $37^{\circ} \mathrm{C}$ aerobically. Cultures were diluted at 1:100 in freshly prepared sterile TSB. Aliquots of $200 \mu \mathrm{L}$ from diluted cultures were inoculated in individual wells of sterile flat-bottomed 96-well tissue culture polystyrene plates (Sigma-Aldrich, USA). E. coli ATCC 25922 was used as the positive control, and a sterile broth was used as the negative control. Plates were incubated at $37^{\circ} \mathrm{C}$ for $24 \mathrm{~h}$. After incubation, the broth was removed, and the wells were washed thrice with $200 \mu \mathrm{L}$ sterile normal saline. After air-drying at room temperature for $20 \mathrm{~min}$, the wells were stained with $200 \mu \mathrm{L}$ of $1 \%$ crystal violet solution for $5 \mathrm{~min}$. After staining, the plates were rinsed with $200 \mu \mathrm{L}$ sterile deionized distilled water and airdried for $1 \mathrm{~h}$ at $25^{\circ} \mathrm{C}$. The optical density (OD) of the stained wells was measured at a wavelength of $540 \mathrm{~nm}$ using an enzyme-linked immunosorbent assay reader (BioTek-800 ST, USA). BF was determined according to the formula: $\mathrm{BF}=\mathrm{AB}-\mathrm{CW}$, where $\mathrm{AB}$ is the $\mathrm{OD}$ of the wells attached by bacteria, and CW is the OD of the stained control wells. The experiment was performed in duplicate on three different days. Biofilm production by each isolate was scored as either strong $(\mathrm{BF}=\geq 0.300)$, moderate $(\mathrm{BF}=0.200-0.299)$, weak $(\mathrm{BF}=0.100-0.199)$, or negative $(\mathrm{BF}=<0.100)$.

\section{Detection of virulence genes}

Eight virulence genes linked to different $E$. coli pathotypes (stx1 and stx 2 genes [EHEC], eae and ehxA genes [EHEC/EPEC], est and elt genes [ETEC], $b f p A$ gene [EPEC], and $\operatorname{agg} R$ gene [enteroaggregative $E$. coli or EAEC]) and two serotype-related genes
( rbfO157 and $f l i C H 7$ genes [EHEC]) were investigated by real-time quantitative PCR (qPCR) according to the methods of Cabal et al. [21]. For the rapid molecular identification of APEC isolates, five specific genes (iss, iutA, hlyF, ompT, and iroN) were amplified by qPCR according to Ikuta et al. [22]. The primers and PCR conditions are illustrated in Table-1 [21,22].

\section{Statistical analysis}

The Fisher's exact test or $\chi^{2}$ test and Spearman's rank correlation test using GraphPad Prism 8 (GraphPad Software, San Diego, CA 92108, USA) were used to determine the statistical significance of the data.

\section{Results}

\section{Bacterial isolation}

Eighty-six E. coli strains were isolated from 30 backyard chicken flocks. Isolates were biochemically identified to the species level. Genetically, sequences of the $16 \mathrm{~S} r R N A$ gene showed $>98 \%$ identity with $E$. coli in the NCBI database. Representative sequences were deposited in the NCBI sequences database with GenBank accession numbers MW366906, MW366747, MW368769 to MW368781, and MZ413447 to MZ413460. The frequency of isolation from diseased flocks was significantly higher $(\mathrm{p}<0.05)$ than apparently healthy flocks. Figure-1 shows the distribution of isolates concerning the clinical status of the flocks and the sampling site.

\section{Antimicrobial susceptibility}

The antimicrobial susceptibility profile of the $86 \mathrm{E}$. coli isolates is shown in Figure-2. In this study, E. coli isolates showed high resistance to AMP (75.6\%), GEN (39.5\%), and TCY (29.1\%). However, none of the isolates were resistant to IPM. The resistance rate was significantly higher $(\mathrm{p}<0.05)$ in $E$. coli strains isolated from diseased birds than healthy birds. However, intestinal isolates showed a non-significantly higher $(\mathrm{p}>0.05)$ resistance rate

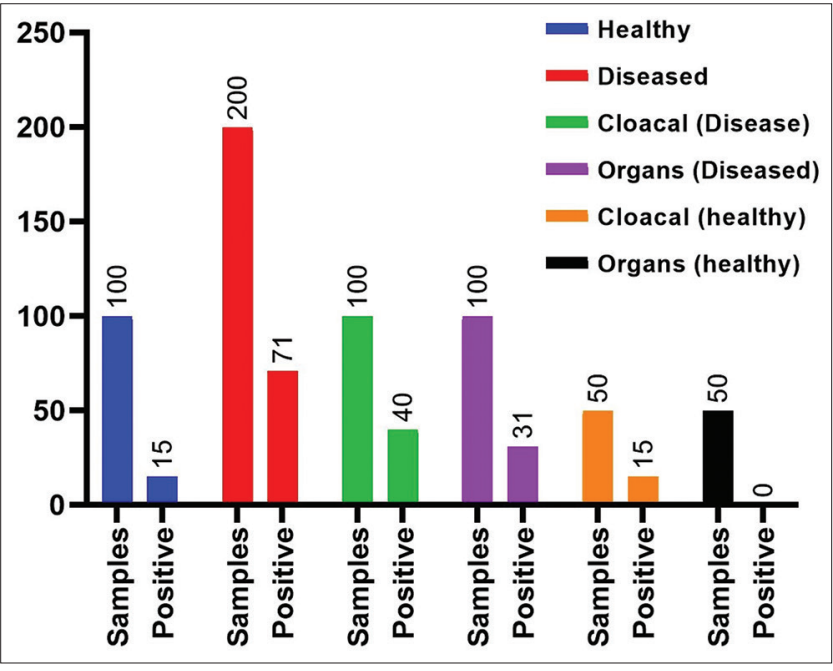

Figure-1: Distribution of Escherichia coli isolates $(n=86)$ concerning the clinical status of the flocks and the site of sampling. 
Table-1: Primers, probes, and melting temperature used in amplification of different virulence genes.

\begin{tabular}{|c|c|c|c|c|c|}
\hline Primers & Target & $\begin{array}{l}\text { Oligonucleotide sequence } \\
\left(5 \times \text { à } 3^{\prime}\right)\end{array}$ & $\begin{array}{c}\text { Melting } \\
\text { temperature }\end{array}$ & $\begin{array}{l}\text { Amplicon } \\
\text { (bp) }\end{array}$ & Reference \\
\hline $\begin{array}{l}\text { iss-F } \\
\text { iss-R } \\
\text { FAM }\end{array}$ & $\begin{array}{l}\text { Increases serum survival } \\
\text { gene }\end{array}$ & $\begin{array}{l}\text { CGGGAATTGGACAAGAGAAAAC } \\
\text { TITCTGCACCGCCACAAA } \\
\text { TIGGCTGCATCAAC }\end{array}$ & 60 & 57 & [22] \\
\hline $\begin{array}{l}\text { iutA-F } \\
\text { iutA-R } \\
\text { VIC }\end{array}$ & $\begin{array}{l}\text { Ferric aerobactin receptor } \\
\text { gene }\end{array}$ & $\begin{array}{l}\text { CGGTGGCGTACGCTATCAGT } \\
\text { GCGCGTAGCCGATGAAAT } \\
\text { CACTGAAAACAAGATTGAT }\end{array}$ & 60 & 59 & \\
\hline $\begin{array}{l}\text { hlyF-F } \\
\text { hlyF-R }\end{array}$ & Putative avian hemolysin & $\begin{array}{l}\text { GGTTGCCCGACCATCAATT } \\
\text { ACTGGTTGAAGGTAAGCACCCTAA }\end{array}$ & 60 & 61 & \\
\hline FAM & & TTGTTGGCCACAGTCG & & & \\
\hline $\begin{array}{l}\text { ompT-F } \\
\text { ompT-R }\end{array}$ & $\begin{array}{l}\text { Episomal outer membrane } \\
\text { protease gene }\end{array}$ & $\begin{array}{l}\text { GGTTCCGGGATTGCTCGTAT } \\
\text { GGTCGTGGAGGCAATATGGT }\end{array}$ & 60 & 57 & \\
\hline VIC & & CAGCCAGTCCCTGTC & & & \\
\hline $\begin{array}{l}\text { iroN-F } \\
\text { iroN-R } \\
\text { FAM }\end{array}$ & $\begin{array}{l}\text { Salmochelin siderophore } \\
\text { receptor gene }\end{array}$ & $\begin{array}{l}\text { CCGTTGGTGCAGAGTGGAA } \\
\text { CAGGCTGGTAGAGGAAGGATCA }\end{array}$ & 60 & 53 & \\
\hline $\begin{array}{l}\text { FAM } \\
\text { st } \times 1-F\end{array}$ & Shiga toxin 1 (st $\times 1)$ & $\begin{array}{l}\text { CGCGATAAGCTCG } \\
\text { GCAAAGAMGTATGTWGATTCG }\end{array}$ & 55 & 107 & [21] \\
\hline st $\times 1-R$ & & GWGCCACTATCAATCATCAG & & & \\
\hline st $\times 2-\mathrm{F}$ & Shiga toxin 2 (st $\times 2)$ & AATGCAAATCAGTCGTCAC & 55 & 82 & \\
\hline st $\times 2-R$ & & TGCATCTCTGGTCATTGTAT & & & \\
\hline FAM & & CACTGGTITCATCATATCTGGCGTT & & & \\
\hline eae-F & Intimin & GCTATAACRTCTTCATTGATC & 52 & 92 & \\
\hline eae-R & & RCTACTITTRAAATAGTCTCG & & & \\
\hline FAM & & TTCGCCACCAATACCTAAACGG & & & \\
\hline ehxA-F & Enterohaemolysin (ehxA) & GCACCACAACTTGAYAAACT & 55 & 86 & \\
\hline ehxA-R & & CCAGATTATTACCTACATTYTCAG & & & \\
\hline FAM & & TTTACTCCCAACGTTCTGATACTTCTG & & & \\
\hline est-F & ST toxin (est) & TGAAAGCATGAATRGTAGCAA & 54 & 72 & \\
\hline est-R & & TTAATAACATSSAGCACAGG & & & \\
\hline FAM & & CAGGATTACAACAMARTTCACAGCAGT & & & \\
\hline elt-F & LT toxin (elt) & GGYAAAAGAGAAATGGTTAT & 54 & 142 & \\
\hline elt-R & & TCTCGGTCAGATATGYGATTC & & & \\
\hline ROX & & TGTGTCCTTCATCCTTTCAATGGC & & & \\
\hline bfpA-F & Bundle- forming pilus & CMGGTGTGATGTITTACTAC & 53 & 109 & \\
\hline bfpA-R & $(\mathrm{bfpA})$ & TGCCCAATATACARACCAT & & & \\
\hline FAM & & AGTCTGCGTCTGATTCCAATAAGKC & & & \\
\hline invA-F & Invasion plasmid (spa24) & CCAATCACAATATCAGTACCA & 53 & 159 & \\
\hline invA-R & & AAAGAGCCTTATTACCCATAT & & & \\
\hline ROX & & AGACACATTACCTCCATCATCTAAGCA & & & \\
\hline aggR-F & Enteroaggregative & TTTATCGCAATCAGATTAARC & 56 & 94 & \\
\hline aggR-R & regulator (aggR) & GGACAACTRCAAGCATCTAC & & & \\
\hline ROX & & ACATTAAGACGCCTAAAGGATGCC & & & \\
\hline rfb 0157-F & rbfO157 & CAAAAGGAAACTATATTCAGAAGT & 55 & 125 & \\
\hline rfb O157-R & & CGATATACCTAACGCTAACAA & & & \\
\hline FAM & & АTTCСTCTCTTTCCTCTGCGGTC & & & \\
\hline Wzx 0104-F & wzxO104 & GCGCAAAGAATTTCAACTT & 55 & 99 & \\
\hline wzx O104-R & & TGTAAAATCCTITAAACTATACG & & & \\
\hline ROX & & TGAAATGACACCACTTATTGCTAATACA & & & \\
\hline
\end{tabular}

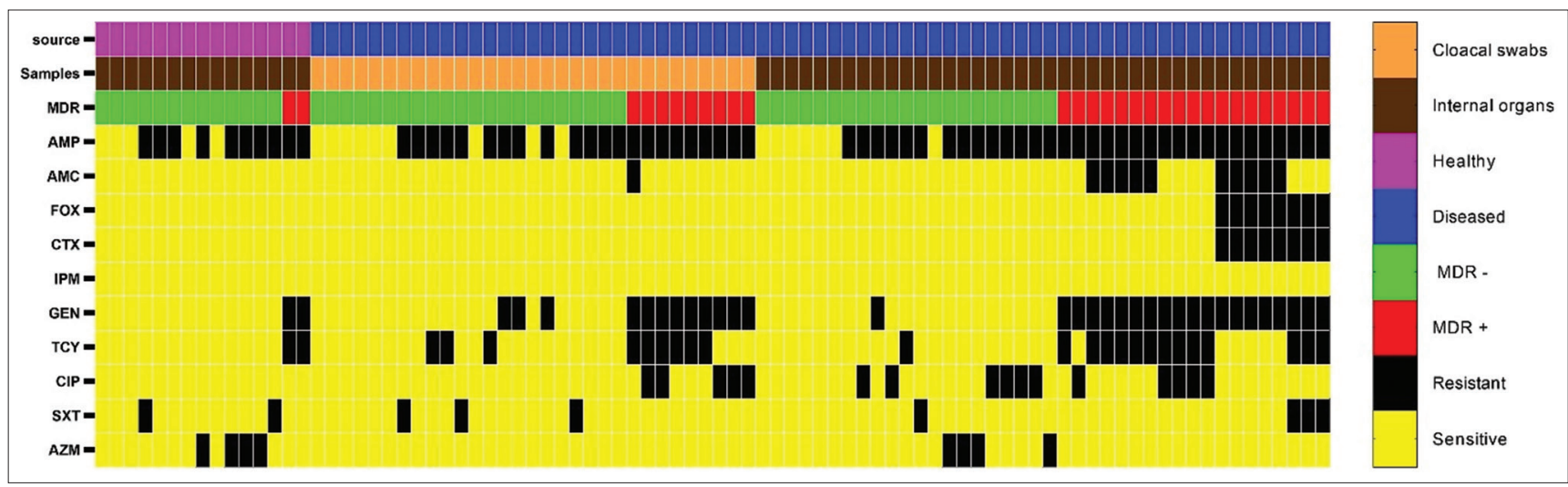

Figure-2: Heat map representation of the antimicrobial-resistant profile of Escherichia coli isolates $(n=86)$ recovered from healthy and diseased backyard chickens. 
than extraintestinal isolates. The MIC50, MIC90, and MIC range for the ten antibiotics are shown in Table2. The pairwise correlation between antimicrobial MIC values and E. coli isolates is shown in Figure-3. The strongest, statistically significant $(\mathrm{p}<0.001)$ correlations were between TCY and GEN ( $\mathrm{r}=0.61)$, FOX and AMC ( $\mathrm{r}=0.64)$, FOX and CTX $(\mathrm{r}=0.58)$, and AMP and AMC $(\mathrm{r}=0.47)$. The drug resistance profile of E. coli isolates is presented in Table-3. Overall, $21(24.4 \%)$ isolates were sensitive to all ten antimicrobials. Seven $(8.1 \%)$ isolates were resistant only to AMP, and $28(32.6 \%)$ were resistant to two antimicrobials, whereas the remaining $30(34.9 \%)$ isolates showed multidrug resistance (MDR). Based on the MDR index, 30 (34.9\%) isolates showed an MDR index of $>0.2$, and $28(32.6 \%)$ isolates showed an MDR index of $<0.2$. Of the 86 isolates, $8(9.3 \%)$ were confirmed as ESBL-producing E. coli by the combination disk diffusion method. All ESBL isolates were MDR with an MDR index of 0.5 to 0.6 .

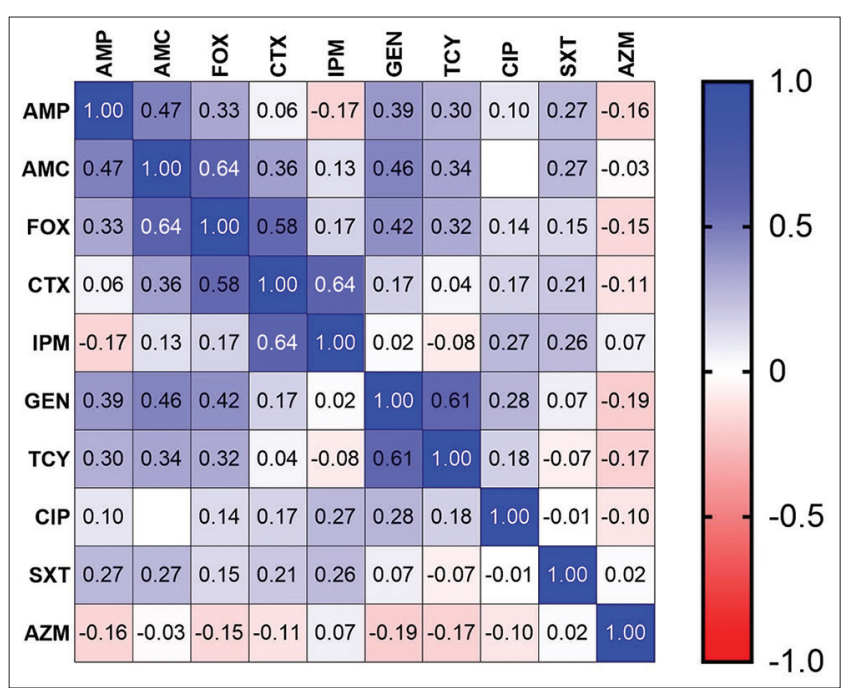

Figure-3: Spearman rank correlation coefficient between the antimicrobials based on minimum inhibitory concentration of 86 Escherichia coli isolates.
BF

The results of the MTP method revealed that $57(66.27 \%)$ isolates were capable of forming biofilms. Based on the corrected $\mathrm{OD}_{540 \mathrm{~nm}}$ of the bacterial biofilm, the isolates were categorized into four groups: Strong, moderate, weak, and negative. Of the 86 isolates, $22(25.6 \%)$ were strong biofilm producers, 24 (27.9\%) moderate producers, 11 (12.8\%) weak producers, and $29(33.7 \%)$ were unable to form biofilm. The mean of the corrected OD values for each group is shown in Figure-4. The correlation between both identified MDR isolates and MRD index and BF was investigated. A statistically significant $(\mathrm{p}<0.001)$ pairwise correlation was obtained for MDR versus $\mathrm{BF}(\mathrm{r}=0.512)$ and MRD index versus $\mathrm{BF}(\mathrm{r}=0.556)$. The mean values of the MDR index in each group are shown in Figure-4. The distribution of the four BF groups among $E$. coli strains isolated from healthy and diseased birds and the strains that exhibited MDR profile is shown in Figure-5. MDR isolates showed a significantly strong and moderate BF than weak and negative producers $(\mathrm{p}>0.05)$. E. coli strains isolated from diseased birds showed a significant strong $\mathrm{BF}$ ( $>0.05$ ).

\section{Virulence genotyping}

In general, each of the 14 virulence-associated genes was investigated in the 86 isolates. Thirteen virulence genes were identified with varying degrees of frequency; however, the invA gene was not identified in any isolate. The higher frequency of virulence genes was statistically significant in $E$. coli isolated from diseased birds than healthy birds $(\mathrm{p}<0.001)$. The distribution of different virulence genes is illustrated in Figure-6. Based on virulence gene profiles, five pathotypes were identified: EPEC (39.5\%), APEC $(32.53 \%)$, EHEC (9.3\%) EAEC (1.2\%), and ETEC (5.8\%). The lower frequency of EAEC and ETEC was statistically significant than other pathotypes. Ten $(11.6 \%)$ isolates were identified as nonpathogenic E. coli. A BF was reported in all EPEC pathotypes,

Table-2: The MIC50, MIC90, and MIC range and resistance percentage of Escherichia coli $(\mathrm{n}=86)$ isolate from healthy and diseased birds.

\begin{tabular}{|c|c|c|c|c|c|c|c|c|c|}
\hline \multirow[t]{3}{*}{ Antibiotic } & \multirow[t]{3}{*}{ No. } & \multirow[t]{3}{*}{$\mathbf{R} \%$} & \multirow[t]{3}{*}{ MIC50 } & \multirow[t]{3}{*}{ MIC90 } & \multirow[t]{3}{*}{ MIC Range } & \multicolumn{4}{|c|}{ No. of resistant E. coli (\%) } \\
\hline & & & & & & \multicolumn{2}{|c|}{ Clinical status } & \multicolumn{2}{|c|}{ Sample site } \\
\hline & & & & & & Normal Birds & Diseased Birds & Cloacal swabs & Internal organs \\
\hline AMP & 65 & 75.6 & 64 & 128 & $1-164$ & $10(15.4)$ & $55(84.6)$ & $43(66.1)$ & $22(33.9)$ \\
\hline AMC & 11 & 12.8 & 4 & 32 & $1-64$ & $0(0.0)$ & $11(100)$ & $10(90.9)$ & $1(9.1)$ \\
\hline CTX & 8 & 9.3 & 0.5 & 1 & $0.125-16$ & $0(0.0)$ & $8(100)$ & $8(100)$ & $0(0.0)$ \\
\hline FOX & 8 & 9.3 & 4 & 8 & $0.5-64$ & $0(0.0)$ & $8(100)$ & $8(100)$ & $0(0.0)$ \\
\hline IPM & 0 & 0 & 0.25 & 1 & $0.125-1$ & $0(0.0)$ & $0(0.0)$ & $0(0.0)$ & $0(0.0)$ \\
\hline GEN & 34 & 39.5 & 4 & 32 & $1-64$ & $2(5.9)$ & $32(94.1)$ & $22(64.7)$ & $12(35.3)$ \\
\hline CIP & 16 & 18.6 & 0.125 & 4 & $0.125-8$ & $0(0.0)$ & $16(100)$ & $11(68.8)$ & $5(31.2)$ \\
\hline SXT & 9 & 10.5 & 2 & 8 & $1-16$ & $2(22.2)$ & $7(77.8)$ & $6(66.7)$ & $3(33.3)$ \\
\hline AZM & 8 & 9.3 & 8 & 16 & $2-64$ & $4(50)$ & $4(50)$ & $8(100)$ & $0(0.0)$ \\
\hline TCY & 25 & 29.1 & 4 & 32 & $2-64$ & $2(8)$ & $23(98)$ & $16(64)$ & $9(36)$ \\
\hline
\end{tabular}

$M D R=$ Multidrug resistance, $A M P=$ Ampicillin, $A M C=$ Amoxicillin-clavulanate, $F O X=C$ efoxitin, IPM=Imipenem, GEN=Gentamicin, MIC=Minimum inhibitory concentration, CTX=Cefotaxime, TCY=Tetracycline, SXT=Trimethoprim/ sulfamethoxazole, AZM=Azithromycin 
Table-3: Drug resistance profile and MDR index of Escherichia coli isolates $(\mathrm{n}=86)$.

\begin{tabular}{lcc}
\hline Resistance profile & $\begin{array}{c}\text { Number of } \\
\text { isolates }(\%)\end{array}$ & MAR index \\
\hline & $21(24.4)$ & 0 \\
AMP & $7(8.1)$ & 0.1 \\
AMP AZM & $8(9.3)$ & 0.2 \\
AMP SXT & $6(7)$ & 0.2 \\
AMP CIP & $6(7)$ & 0.2 \\
AMP TCY & $4(4.7)$ & 0.2 \\
AMP GEN & $4(4.7)$ & 0.2 \\
AMP GEN CIP & $4(4.7)$ & 0.3 \\
AMP GEN TCY & $6(7)$ & 0.3 \\
AMP GEN TCY CIP & $6(7)$ & 0.4 \\
AMP AMC GEN TCY & $6(7)$ & 0.4 \\
AMP AMC FOX CTX GEN & $5(5.8)$ & 0.5 \\
AMP FOX CTX GEN TCY SXT & $3(3.5)$ & 0.6 \\
\hline
\end{tabular}

$\mathrm{MDR}=$ Multidrug resistance, $\mathrm{AMP}=$ Ampicillin, $A M C=$ Amoxicillin-clavulanate, $F O X=$ Cefoxitin, IPM=Imipenem, GEN=Gentamicin, MAR=Multiple antibiotic resistance, CTX=Cefotaxime, TCY=Tetracycline, SXT=Trimethoprim/sulfamethoxazole, AZM=Azithromycin

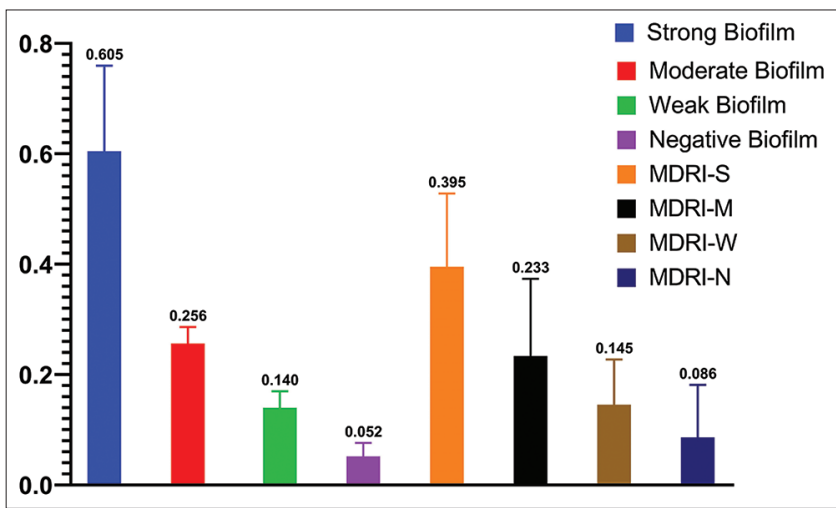

Figure-4: Biofilm formation: the mean OD of strong, moderate, weak, and negative biofilm producer Escherichia coli and the mean value of multidrug resistance index in each group.

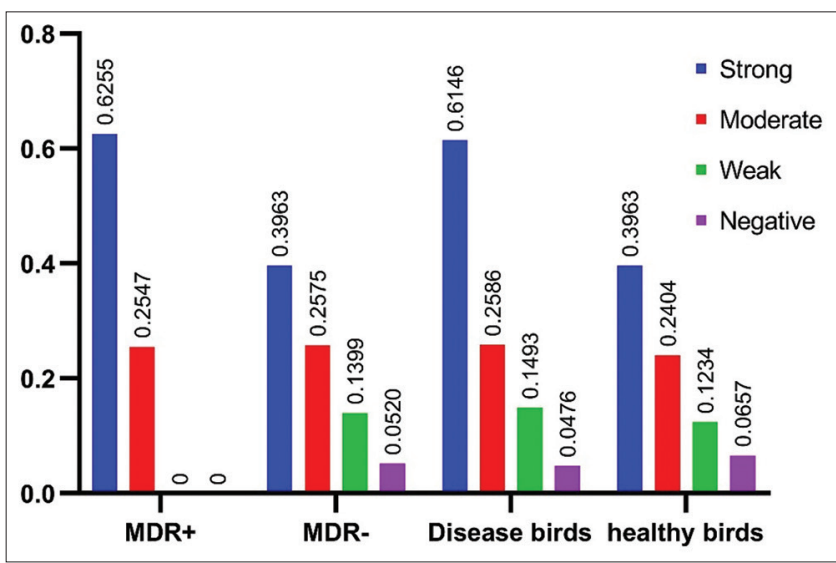

Figure-5: The distribution of the four biofilm formation groups among Escherichia coli strains isolated from healthy and diseased birds and the strains that exhibited multidrug resistance profile.

and 19 (65.5\%) showed MDR profiles. Table-4 shows the virulence genes, BF, and MDR in different $E$. coli pathotypes. Of the eight EHEC pathotypes, three isolates were $s t x 1^{+}-s t x 2^{+}, 2$ isolates were $s t x 1^{+}-s t x 2^{-}$, and three isolates were $s t x 1^{-}-s t x 2^{+}$. Three isolates were identified as $\mathrm{O} 157$ based on the detection of the rbfO157 gene.

\section{Discussion}

Although backyard chicken flocks have traditionally been regarded as an essential food source in developed countries, backyard chickens may act as a reservoir and spread various zoonotic bacterial pathogens. Free-living chickens in backyard flocks increase the risk of gaining bacterial pathogens from wild animals or birds. Furthermore, close contact with humans facilitates the transmission of zoonotic pathogens [23]. In this study, E. coli was isolated from $40 \%$ and $31 \%$ of cloacal swabs and internal organs, respectively, collected from diseased chickens. However, in healthy chickens, E. coli was only recovered from $30 \%$ of cloacal swabs. The frequency of isolation in this study was relatively lower than the previously reported study in Malaysia (48\%) [24] and similar to that reported in Egypt (34\%) [25] and Ethiopia $(32.5 \%)$ [26]. The variation in isolation frequency may be attributed to the sampling size, type of samples, and breeding system.

Antibiotic resistance development, transmission, and persistence remain major concerns, particularly in low- and middle-income countries, where small-scale animal husbandry is prevalent $[27,28]$. In this study, $E$. coli isolates showed variable resistance to the ten antibiotics. High resistance was reported to AMP (75.6\%), GEN (39.5\%), and TYC (29.1\%). This result was consistent with previous studies [29-31], which reported $74 \%, 41 \%$, and $32 \%$ resistance to the three antibiotics in Brazil, Jordan, and Thailand, respectively. However, higher resistance to AMP (94\%) and TYC (100\%) was reported in Zimbabwe [32] and Spain [33], whereas a lower resistance to GEN (24\%) was reported in Thailand [31].

The results revealed that $34.9 \%$ of the isolates presented MDR profiles to three and up to six antimicrobials. The emergence of MDR E. coli has been previously reported and is currently regarded as a growing public health concern [34-36]. The high incidence of antimicrobial resistance reported within or between antimicrobial classes in multiple investigations might be attributed to the extensive, indiscriminate, and long-term usage of comparable medicines in chicken farms [37].

In this study, $9.3 \%$ of the isolates showed ESBL activity; however, carbapenemase activity was not observed in any isolate. These findings were corroborated by earlier studies on the presence of ESBLproducing $E$. coli in chickens [34,38,39]. However, a higher frequency of ESBL (58.6\% and 29\%) was reported in Egypt [40] and Ghana [41], whereas a lower frequency $(5.1 \%)$ was recorded in Germany [42]. ESBL activity in Enterobacteriaceae poses a severe public health risk because of the ability of these bacteria to hydrolyze third-generation cephalosporins 


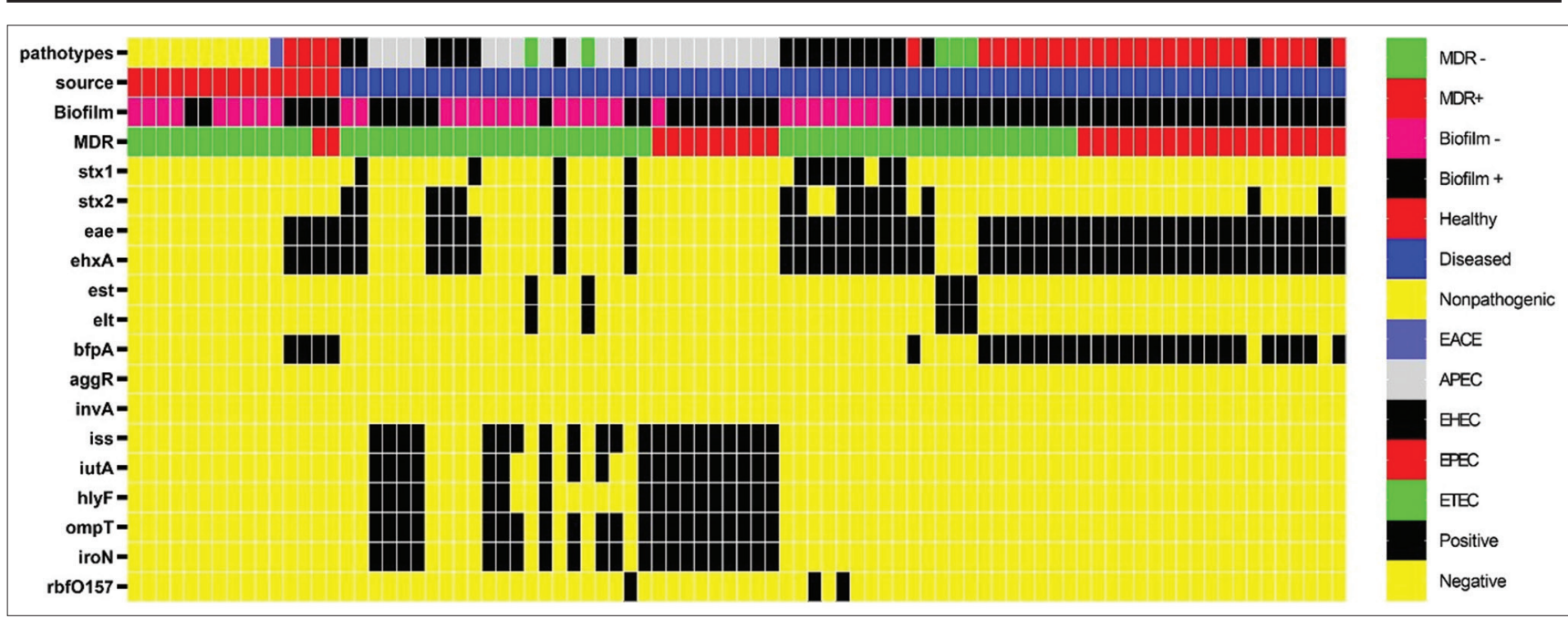

Figure-6: Heat map representation of virulence gene profile of Escherichia coli isolates $(n=86)$ recovered from healthy and diseased backyard chickens.

Table-4: Virulence genes, biofilm formation, and MDR in different Escherichia coli pathotypes.

\begin{tabular}{|c|c|c|c|c|c|c|c|c|c|c|c|c|c|c|c|c|c|}
\hline \multirow[t]{2}{*}{ Pathotype } & \multirow[t]{2}{*}{ NO } & \multirow[t]{2}{*}{ MDR } & \multirow[t]{2}{*}{ Biofilm } & \multicolumn{14}{|c|}{ Virulence genes } \\
\hline & & & & stx 1 & stx 2 & eae & $e h \times A$ & est & elt & bfpA & $\operatorname{aggR}$ & invA & iss & iutA & hlyF & ompt & iron \\
\hline APEC & 28 & 9 & 16 & 0 & 0 & 0 & 0 & 0 & 0 & 0 & 0 & 0 & 28 & 26 & 23 & 28 & 28 \\
\hline EAEC & 1 & 0 & 0 & 0 & 0 & 0 & 0 & 0 & 0 & 0 & 1 & 0 & 0 & 0 & 0 & 0 & 0 \\
\hline EHEC & 8 & 2 & 3 & 5 & 6 & 8 & 8 & 0 & 0 & 0 & 0 & 0 & 0 & 0 & 0 & 0 & 0 \\
\hline EPEC & 34 & 19 & 31 & 0 & 0 & 34 & 34 & 0 & 0 & 34 & 0 & 0 & 0 & 0 & 0 & 0 & 0 \\
\hline ETEC & 5 & 0 & 3 & 0 & 0 & 0 & 0 & 5 & 5 & 0 & 0 & 0 & 0 & 0 & 0 & 0 & 0 \\
\hline Non-Path & 10 & 0 & 4 & 0 & 0 & 0 & 0 & 0 & 0 & 0 & 0 & 0 & 0 & 0 & 0 & 0 & 0 \\
\hline
\end{tabular}

$\mathrm{MDR}=$ Multidrug resistance, $\mathrm{EHEC}=$ Enterohemorrhagic Escherichia coli, EPEC=Enteropathogenic Escherichia coli, $\mathrm{ETEC}=$ Enterotoxigenic Escherichia coli, $\mathrm{APEC}=$ Avian pathogenic Escherichia coli

classified by the World Health Organization as the highest priority critically important antimicrobials for human medicine [43].

BF by $E$. coli has been recognized as an essential factor associated with its virulence [44]. In this work, BF was detected by the MTP method in $66.27 \%$ of the isolates. Similar results $(62.5 \%$ and $68 \%)$ were reported in Uganda [11] and Czech Republic [45], and relatively lower (55.8\%) BF was reported by Rodrigues et al. [12]. E. coli recovered from diseased birds showed a significantly strong BF. These findings were confirmed by Lewis [46], who reported that bacterial biofilms are considered to be involved in $\sim 65 \%$ of all bacterial infections. This study revealed a statistically significant correlation between MDR and BF. This agreed with previous reports in Uganda [11] and Spain [47]. High resistance of biofilm bacteria to antimicrobials is a critical issue in the treatment of infections, and biofilm cells are thought to be 100-1000 times more resistant to antimicrobial treatments than planktonic bacterial cells $[10,48]$.

qPCR is a rapid and accurate method for diagnosis. In this study, 14 virulence genes were detected by TaqMan real-time PCR, and $24.4 \%$ of the isolates were identified as APEC based on the five common genes (iss, iutA, ompT, $h l y F$, and iro $N$ ). A relatively higher frequency (36.36\%) was reported in Bangladesh [49] and a lower frequency in Brazil [50]. APEC is the causative agent of colibacillosis, a highly fatal septicemic disease of chickens that causes significant economic losses in the poultry industry worldwide [51]. Unfortunately, eight isolates were identified as EHEC pathotypes. This result was consistent with Wang et al. [52] and documented by Kim et al. [5], who reviewed that domestic poultry, including turkeys, duck, and chicken, are reservoirs for EHEC.

\section{Conclusion}

This study investigated the antimicrobial resistance, virulence genes, and BF in E. coli strains isolated from backyard chicken in the eastern region of Saudi Arabia. High resistance to different classes of antimicrobials was identified, suggesting the misuse of antimicrobials in backyard chicken farms. The emergence of ESBL and EHEC isolates in backyard chickens is a public health concern. The environment of backyard flocks may harbor different pathogenic bacteria that may enhance the persistence of infection and the transmission to in-contact humans. Therefore, regular monitoring for the occurrence of MDR and the zoonotic pathotypes among $E$. coli in backyard chicken flocks is recommended, as these bacteria can transmit to humans through food products or contaminated environments.

\section{Authors' Contributions}

MF and TA: Conceptualization; MF, TA, AA, RA, and AAA: Methodology. MF and RA: Software. MF 
and AAA: Validation. TA and AA: Formal analysis. AA, AAA, and RA: Investigation. TA and RA: Resources. AA, AAA, and RA: Data curation. MF and TA: Original draft preparation. MF, TA, and RA: Review and editing. TA, AA, and AAA: Visualization. MF: Supervision. All authors read and approved the final manuscript.

\section{Acknowledgments}

The authors would like to extend their appreciation and thanks to Ministry of Environment, Water and Agriculture, Saudi Arabia, for assistance and providing laboratory facilities till the completion of this study. The authors did not receive any funds for this study.

\section{Competing Interests} interests.

The authors declare that they have no competing

\section{Publisher's Note}

Veterinary World remains neutral with regard to jurisdictional claims in published institutional affiliation.

\section{References}

1. Denamur, E., Clermont, O., Bonacorsi, S. and Gordon, D. (2021) The population genetics of pathogenic Escherichia coli. Nat. Rev. Microbiol., 19(1): 37-54.

2. Santos, A.C.M., Santos, F.F., Silva, R.M. and Gomes, T.A. (2020) Diversity of hybrid-and hetero-pathogenic Escherichia coli and their potential implication in more severe diseases. Front. Cell Infect. Microbiol., 10: 339.

3. Russo, T.A. and Johnson, J.R. (2000) Proposal for a new inclusive designation for extraintestinal pathogenic isolates of Escherichia coli: ExPEC. J. Infect. Dis., 181(5): 1753-1754.

4. Kim, Y.B., Yoon, M.Y., Ha, J.S., Seo, K.W., Noh, E.B., Son, S.H. and Lee, Y.J. (2020) Molecular characterization of avian pathogenic Escherichia coli from broiler chickens with colibacillosis. Poult. Sci., 99(2): 1088-1095.

5. Kim, J.S., Lee, M.S. and Kim, J.H. (2020) Recent updates on outbreaks of shiga toxin-producing Escherichia coli and its potential reservoirs. Front. Cell Infect. Microbiol., 10: 273 .

6. Buuck, S., Smith, K., Fowler, R.C., Cebelinski, E., Lappi, V., Boxrud, D., and Medus, C. (2020) Epidemiology of enterotoxigenic Escherichia coli infection in Minnesota, 2016-2017. Epidemiol. Infect., 148: e206.

7. Nhung, N.T., Cuong, N.V., Thwaites, G. and CarriqueMas, J. (2016) Antimicrobial usage and antimicrobial resistance in animal production in Southeast Asia: A review. Antibiotics, 5(4): 37.

8. Kheiri, R. and Akhtari, L. (2016) Antimicrobial resistance and integron gene cassette arrays in commensal Escherichia coli from human and animal sources in IRI. Gut Pathog., 8(1): 40.

9. Donlan, R.M. and Costerton, J.W. (2002) Biofilms: Survival mechanisms of clinically relevant microorganisms. Clin. Microbiol. Rev., 15(2): 167-193.

10. Mah, T.F. and O'Toole, G.A. (2001) Mechanisms of biofilm resistance to antimicrobial agents. Trends Microbiol., 9(1): 34-39.

11. Katongole, P., Nalubega, F., Florence, N.C., Asiimwe, B. and Andia, I. (2020) Biofilm formation, antimicrobial susceptibility and virulence genes of Uropathogenic Escherichia coli isolated from clinical isolates in Uganda. BMC Infect. Dis., 20(1): 453.
12. Rodrigues, S.V., Laviniki, V., Borges, K.A., Furian, T.Q., Moraes, H.L., Nascimento, V.P., and Salle, C.T. (2019) Biofilm formation by avian pathogenic Escherichia coli is not related to in vivo pathogenicity. Curr. Microbiol., 76(2): 194-199.

13. Elhadi, N., Aljindan, R., Alsamman, K., Alomar, A., and Aljeldah, M. (2020) Antibiotic resistance and molecular characterization of enteroaggregative Escherichia coli isolated from patients with diarrhea in the Eastern Province of Saudi Arabia. Heliyon, 6(4): e03721.

14. Sharaf, E.F. and Shabana, I.I. (2017) Prevalence and molecular characterization of Shiga toxin-producing Escherichia coli isolates from human and sheep in Al-Madinah Al-Munawarah. Infectio, 21(2): 81-87.

15. Alqasim, A., Jaffal, A.A., Almutairi, N., Arshad, M. and Alyousef, A.A. (2020) Isolation, phenotypic and genotypic characterization of Escherichia coli from the bloodstream samples in Riyadh, Saudi Arabia. J. King Saud Univ. Sci., 32(2): 1464-1469.

16. Aabed, K., Moubayed, N. and Alzahrani, S.J. (2021) Antimicrobial resistance patterns among different Escherichia coli isolates in the Kingdom of Saudi Arabia. Saudi J. Biol. Sci., 28(7): 3776-3782.

17. El-Ghareeb, W.R., Abdel-Raheem, S.M., Al-Marri, T.M., Alaql, F.A. and Fayez, M.M. (2020) Isolation and identification of extended-spectrum $\beta$-lactamases (ESBLs) Escherichia coli from minced camel meat in Eastern province, Saudi Arabia. Thai J. Vet. Med., 50(2): 155-161.

18. Weisburg, W.G., Barns, S.M., Pelletier, D.A. and Lane, D.J. (1991) 16S ribosomal DNA amplification for phylogenetic study. J. Bacteriol., 173(2): 697-703.

19. Clinical and Laboratory Standards Institute. (2021) Performance Standards for Antimicrobial Susceptibility Testing, CLSI Supplement M100. 31 st ed. Clinical and Laboratory Standards Institute, United States.

20. Naves, P., Del Prado, G., Huelves, L., Gracia, M., Ruiz, V., Blanco, J., Rodríguez-Cerrato, V., Ponte, M.C. and Soriano, F. (2008) Measurement of biofilm formation by clinical isolates of Escherichia coli is method-dependent. $J$. Appl. Microbiol., 105(2): 585-590.

21. Cabal,A., Geue, L., Gomez-Barrero, S., Barth, S., Barcena, C., Hamm, K., Porrero, M.C., Valverde, A., Canton, R., Menge, C., Gortazar, C., Dominguez, L. and Alvarez, J. (2015) Detection of virulence-associated genes characteristic of intestinal Escherichia coli pathotypes, including the enterohemorrhagic/enteroaggregative O104:H4, in bovines from Germany and Spain. Microbiol. Immunol., 59(8): 433-442.

22. Ikuta, N., De Oliveira Solla Sobral, F., Lehmann, F.K., da Silveira, P.V., de Carli, S., Casanova, Y.S., Celmer, A.J., Fonseca, A.S. and Lunge, V.R. (2014) Taqman realtime PCR assays for rapid detection of avian pathogenic Escherichia coli isolates. Avian Dis., 58(4): 628-631.

23. Pohjola, L., Rossow, L., Huovilainen, A., Soveri, T., Hanninen, M.L. and Fredriksson-Ahomaa, M. (2015) Questionnaire study and postmortem findings in backyard chicken flocks in Finland. Acta Vet. Scand., 57(1): 1-9.

24. Ibrahim, S., Wei Hoong, L., Lai Siong, Y., Mustapha, Z., Zalati, C.W.S., Aklilu, E., Mohamad, M. and Kamaruzzaman, N.F. (2021) Prevalence of antimicrobial resistance (AMR) Salmonella spp. And Escherichia coli isolated from broilers in the East coast of peninsular Malaysia. Antibiotics, 10(5): 579.

25. Ibrahim, W.A., Marouf, S.A., Erfan, A.M., Nasef, S.A. and Jakee, J.K.E. (2019) The occurrence of disinfectant and antibiotic-resistant genes in Escherichia coli isolated from chickens in Egypt. Vet. World, 12(1): 141-145.

26. Sarba, E.J., Kelbesa, K.A., Bayu, M.D., Gebremedhin, E.Z., Borena, B.M. and Teshale, A. (2019) Identification and antimicrobial susceptibility profile of Escherichia coli isolated from backyard chicken in and around ambo, Central Ethiopia. BMC Vet. Res., 15(1): 85

27. Bui, T.K.N., Bui, T.M.H., Ueda, S., Le, D.T., Yamamoto, Y. 
and Hirai, I. (2018) Potential transmission opportunity of CTX-M-producing Escherichia coli on a large-scale chicken farm in Vietnam. J. Glob. Antimicrob. Resist., 13: 1-6.

28. Hedman, H.D., Eisenberg, J.N., Vasco, K.A., Blair, C.N., Trueba, G., Berrocal, V.J. and Zhang, L.J. (2019) High prevalence of extended-spectrum beta-lactamase CTX-Mproducing Escherichia coli in small-scale poultry farming in rural Ecuador. Am. J. Trop. Med. Hyg., 100(2): 374-376.

29. Braga, J.F.V., Chanteloup, N.K., Trotereau, A., Baucheron, S., Guabiraba, R., Ecco, R. and Schouler, C. (2016) Diversity of Escherichia coli strains involved in vertebral osteomyelitis and arthritis in broilers in Brazil. $B M C$ Vet. Res., 12(1): 1-12.

30. Abu-Basha, E., Gharaibeh, S. and Thabet, A.J. (2012) In vitro susceptibility of resistant Escherichia coli field isolates to antimicrobial combinations. J. Appl. Poult. Res., 21(3): 595-602.

31. Chansiripornchai, N., Mooljuntee, S. and Boonkhum, P.J. (2011) Antimicrobial sensitivity of avian pathogenic Escherichia coli (APEC) isolated from chickens during 2007-2010. Thai J. Vet. Med., 41(4): 519.

32. Saidi, B., Mafirakureva, P. and Mbanga, J. (2013) Antimicrobial resistance of Escherichia coli isolated from chickens with colibacillosis in and around Harare, Zimbabwe. Avian Dis., 57(1): 152-154.

33. Solà-Ginés, M., Cameron-Veas, K., Badiola, I., Dolz, R., Majó, N., Dahbi, G., Viso, S., Mora, A., Blanco, J. and Piedra-Carrasco, N.J.P. (2015) Diversity of multidrug resistant avian pathogenic Escherichia coli (APEC) causing outbreaks of colibacillosis in broilers during 2012 in Spain. PLoS One, 10(11): e0143191.

34. Rahman, M.M., Husna, A., Elshabrawy, H.A., Alam, J., Runa, N.Y., Badruzzaman,A.T.M., Banu, N.A.,Al Mamun, M., Paul, B., Das, S., Rahman, M.M., Mahbub, E.E.A., Khairalla, A.S. and Ashour, H.M. (2020) Isolation and molecular characterization of multidrug-resistant Escherichia coli from chicken meat. Sci. Rep., 10(1): 21999.

35. Brower, C.H., Mandal, S., Hayer, S., Sran, M., Zehra, A., Patel, S.J., Kaur, R., Chatterjee, L., Mishra, S., Das, B.R., Singh, P., Singh, R., Gill, J.P.S. and Laxminarayan, R. (2017) The prevalence of extended-spectrum beta-lactamase-producing multidrug-resistant Escherichia coli in poultry chickens and variation according to farming practices in Punjab, India. Environ. Health Perspect., 125(7): 077015.

36. Shrestha, A., Bajracharya, A.M., Subedi, H., Turha, R.S., Kafle, S., Sharma, S., Neupane, S., and Chaudhary, D.K. (2017) Multidrug resistance and extended-spectrum beta-lactamase producing Gram-negative bacteria from chicken meat in Bharatpur Metropolitan, Nepal. BMC Res. Notes, 10(1): 574.

37. Manyi-Loh, C., Mamphweli, S., Meyer, E. and Okoh, A. (2018) Antibiotic use in agriculture and its consequential resistance in environmental sources: Potential public health implications. Molecules, 23(4): 795.

38. Aworh, M.K., Kwaga, J., Okolocha, E., Harden, L., Hull, D., Hendriksen, R.S. and Thakur, S. (2020) Extended-spectrum $\beta$-lactamase-producing Escherichia coli among humans, chickens and poultry environments in Abuja, Nigeria. One Health Outlook, 2: 8 .

39. Mahmud, Z.H., Kabir, M.H., Ali, S., Moniruzzaman, M., Imran, K.M., Nafiz, T.N., Islam, M.S., Hussain, A., Hakim, S.A.I., Worth, M., Ahmed, D., Johnston, D. and Ahmed, N. (2020) Extended-spectrum beta-lactamase-producing Escherichia coli in drinking water samples from a forcibly displaced, densely populated community setting in Bangladesh. Front. Public Health, 8: 228.

40. Awad, A., Arafat, N. and Elhadidy, M. (2016) Genetic elements associated with antimicrobial resistance among avian pathogenic Escherichia coli. Ann. Clin. Microbiol. Antimicrob., 15(1): 1-8.

41. Falgenhauer, L., Imirzalioglu, C., Oppong, K., Akenten, C.W., Hogan, B., Krumkamp, R., Poppert, S., Levermann, V., Schwengers, O., Sarpong, N., OwusuDabo, E., May, J. and Eibach, D. (2018) Detection and characterization of ESBL-producing Escherichia coli from humans and poultry in Ghana. Front. Microbiol., 9: 3358.

42. Huijbers, P.M., de Kraker, M., Graat, E.A., van Hoek, A.H., van Santen, M.G., de Jong, M.C., van Duijkeren, E. and de Greeff, S.C. (2013) Prevalence of extended-spectrum beta-lactamase-producing Enterobacteriaceae in humans living in municipalities with high and low broiler density. Clin. Microbiol. Infect., 19(6): E256-259.

43. Collignon, P.C., Conly, J.M., Andremont, A., McEwen, S.A., Aidara-Kane, A., Agerso, Y., Andremont, A., Collignon, P., Conly, J. and Dang Ninh, T. (2016) World Health Organization ranking of antimicrobials according to their importance in human medicine: A critical step for developing risk management strategies to control antimicrobial resistance from food animal production. Clin. Infect. Dis., 63(8): 1087-1093.

44. Boll, E.J., Struve, C., Boisen, N., Olesen, B., Stahlhut, S.G. and Krogfelt, K.A. (2013) Role of enteroaggregative Escherichia coli virulence factors in uropathogenesis. Infect. Immun., 81(4): 1164-1171.

45. Pavlickova, S., Klancnik, A., Dolezalova, M., Mozina, S.S. and Holko, I. (2017) Antibiotic resistance, virulence factors and biofilm formation ability in Escherichia coli strains isolated from chicken meat and wildlife in the Czech republic. J. Environ. Sci. Health B, 52(8): 570-576.

46. Lewis, K. (2001) Riddle of biofilm resistance. Antimicrob. Agents Chemother., 45(4): 999-1007.

47. Cepas, V., López, Y., Muñoz, E., Rolo, D., Ardanuy, C., Martí, S., Xercavins, M., Horcajada, J.P., Bosch, J. and Soto, S.M. (2019) Relationship between biofilm formation and antimicrobial resistance in gram-negative Bacteria. Microb. Drug Resist., 25(1): 72-79.

48. Costerton, J.W., Stewart, P.S. and Greenberg, E.P. (1999) Bacterial biofilms: A common cause of persistent infections. Science, 284(5418): 1318-1322.

49. Ievy, S., Islam, M., Sobur, M., Talukder, M., Rahman, M. and Khan, M.F. (2020) Molecular detection of avian pathogenic Escherichia coli (APEC) for the first time in layer farms in Bangladesh and their antibiotic resistance patterns. Microorganisms, 8(7): 1021.

50. Borzi, M.M., Cardozo, M.V., Oliveira, E.S., Pollo, A.S., Guastalli, E.A.L., Santos, L.F.D. and Avila, F.A. (2018) Characterization of avian pathogenic Escherichia coli isolated from free-range helmeted guineafowl. Braz. J. Microbiol., 49(1): 107-112.

51. Kathayat, D., Lokesh, D., Ranjit, S. and Rajashekara, G. (2021) Avian pathogenic Escherichia coli (APEC): An overview of virulence and pathogenesis factors, zoonotic potential, and control strategies. Pathogens, 10(4): 467.

52. Wang, S., Zhang, S., Liu, Z., Liu, P., Shi, Z., Wei, J., Shao, D., Li, B. and Ma, Z. (2014) Molecular characterization of enterohemorrhagic E. coli $\mathrm{O} 157$ isolated from animal fecal and food samples in Eastern China. Sci. World J., 2014: 946394. 